\title{
ОСНОВНЫЕ СТРАТЕГИИ УПРАВЛЕНИЯ СТЕЙКХОЛДЕРАМИ В ФАНДРАЙЗИНГОВОЙ ДЕЯТЕЛЬНОСТИ БЛАГОТВОРИТЕЛЬНЫХ ОРГАНИЗАЦИЙ
}

\author{
(c) 2020 Басова Мария Михайловна \\ кандидат экономических наук, доцент \\ доцент Департамента учета, анализа и аудита \\ Финансовый университет при Правительстве Российской Федерации, Россия, Москва \\ E-mail: MMBasova@fa.ru
}

В статье представлены стратегии сбалансированного, взаимовыгодного, носящего регулярный характер взаимодействия благотворительных организаций с участниками фандрайзинговой деятельности (заинтересованными сторонами). Определены ключевые стейкхолдеры, принимающие участие в процессе фандрайзинговой деятельности на примере благотворительного фонда «Дети наши». Для определения баланса их интересов приведена их классификация на основе матрицы А. Менделоу «Влияние-значимость» и модель идентификации значимости заинтересованных сторон Митчелла-Агле-Вуда.

Ключевые слова. Благотворительные организации, стейкхолдеры, матрица классификации стейкходеров, стратегии взаимодействия, фандрайзинг, ключевые доноры, государственные органы, благотворители.

Эффективное взаимодействие с заинтересованными сторонами в процессе фандрайзинговой деятельности позволяет любой благотворительной организации не только упрочить свою репутацию, но и определить возможности для стратегического ее развития с учетом потребностей общества. Под фандрайзингом понимают «деятельность по привлечению ресурсов на некоммерческие проекты, программы, цели. Данное определение подразумевает не только финансовые ресурсы, но и материальные, человеческие, информационные, символические и другие виды. В этой связи сформируем более точное понятие данного термина: «Фандрайзинг - активная деятельность, по привлечению финансовых, материальных, человеческих ресурсов для благотворительных организаций с целью реализации их социально-значимых проектов». Для реализации эффективного управления фандрайзинговой деятельностью необходимо учитывать критерий баланса интересов заинтересованных сторон.

«В книге Эдварда Фримена в 1984 году впервые была предложена полноценная теория управления стейкхолдерами (stakeholder theory). Э.Фримен полагал, что обозначение и выделение тех групп людей, что способны повлиять на бизнес или какой-то отдельный проект, позволят руководителю четко структурировать процесс управления проектами, а также оптимизировать его под свое предприятие. Свою концепцию он представил в шести этапах процесса анализа и управления стейкхолдерами» [6].

Одной из основных функций управления БО является фандрайзинг, который можно рассматривать, как сложный процесс по привлечению финансовых и нефинансовых ресурсов для своей деятельности. Фандрайзинг как функцию управления можно рассматривать как деятельность по привлечению денежных средств и иных ресурсов (материальных, человеческих, информационных и т.д.) из всех возможных каналов и источников финансирования на некоммерческие цели (реализацию определенного проекта или в целом своей деятельности), которые организация не может обеспечить самостоятельно [1]. Если фандрайзинговую деятельность рассматривать, как бизнес процесс, то основываясь на специфике участников фандрайзинговой деятельности и используя основы концепции процесса анализа и управления стейкхолдерами Э. Фримена, разработаем стратегию управления стейкхолдерами в фандрайзинговой деятельности благотворительных организаций.

Анализ фандрайзинговой деятельности большинства благотворительных организаций (БО) России позволил выявить четыре группы заинтересованных сторон: государство; благо- 
получатели; доноры; организации, осуществляющие информационно-технологическую и правовую поддержку.

Стратегия взаимодействия БО с основными группами заинтересованных сторон предусматривает, что с каждым уровнем стейкхолдеров благотворительные организации в ходе фандрайзинговой деятельности взаимодействует по разному, однако смысл един: они предоставляют прозрачную и достоверную отчетность относительно финансов, предоставленных другими субъектами, а спонсоры и благотворители, в свою очередь, вносят пожертвования, как правило, не преследуя корыстных целей и осознают свою помощь для организации. Взаимоотношения частично носят формальный характер, так как финансирование - довольно серьезный аспект благотворительной деятельности. Поэтому спонсоры и жертвователи требуют предоставлять отчетность, с целью наблюдения за деятельностью БФ, так как иначе он может потерять будущее финансирование. С некоторыми субъектами у благотворительных организаций складываются неформальные отношения. Часто это происходит, когда спонсоры и представители организации - знакомые или близкие друзья. В этом случае речь не идет о строгой отчетности перед спонсорами, так как отношения строятся на доверии и взаимопонимании. Поэтому необходим сбалансированный подход, когда, несмотря на то, что преобладает неформальный характер связей между спонсорами и БО, последние предоставляют отчетность и информи- руют население о своей деятельности различными способами.

Стратегия взаимодействия БО с основными группами заинтересованных сторон строится на основе анализа выявленных проблем фандрайзинговой деятельности, основанных на сравнительном подходе требований стейкхолдеров с фактическими параметрами работы организации, а также поддержанию баланса интересов всех заинтересованных сторон некоммерческой организации в процессе принятия решений. Возможное нарушение баланса интересов можно видеть в следующих причинах: установление завышенных целей по привлечению пожертвований; наличие недостатка ресурсов и времени на осуществление фандрайзинговой деятельности; отсутствии комплексной работы по взаимодействию с донорами; неточности в определении мотивов пожертвований и использовании дохода; отсутствии благодарностей для доноров.

Матрица А. Менделоу «Влияние-значимость» позволяет сформировать четыре основные стратегии управления стейкхолдерами. В матрице отражаются все стейкхолдеры экономического субъекта в зависимости от степени их влияния на фандрайзинговую деятельность благотворительной организации и уровня их вовлеченности (рисунок 1).

Основной задачей модели является управление отношениями и взаимосвязями между всеми группами участников фандрайзинговой деятельности таким образом, чтобы обеспечить благотворительному фонду долгосрочный

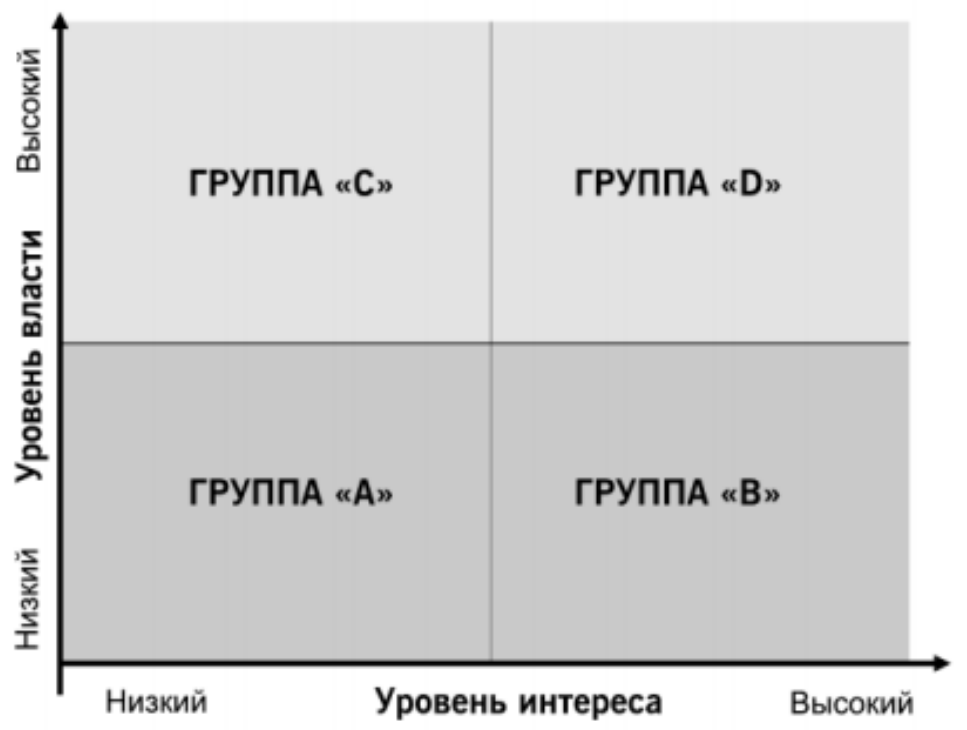

Puc. 1. Матрица классификации стейкхолдеров А. Менделоу 
рост финансовых и нефинансовых ресурсов. Она предполагает активное управление участниками фандрайзинговой деятельности, отношениями внутри фонда и вне его, а также обеспечивает принятие той или иной стратегии фандрайзинговой деятельности благотворительной организации. Рассмотрим основные стратегии управления стейкхолдерами.

Первая стратегия заключается в максимальном вовлечении и применяется к стейкхолдерам с высоким уровнем власти и интереса (Группа D). Данная группа представляет собой основных стейкхолдеров фандрайзинговой деятельности и должна максимально учитываться. Ключевые игроки (группа D) наиболее важны в осуществлении фандрайзинговой деятельности БФ. Ими являются ключевые доноры (коммерческие структуры, грантодатели и частные лица), сотрудники Фонда и фандрайзеры организации, контролирующие органы (Министерство юстиции).

Необходимо повышать заинтересованность группы в фандрайзинговой деятельности и полностью удовлетворять ее потребности. Рекомендуется использовать принцип партнерства в коммуникации при ведении переговоров по привлечению средств с этой группой.

Вторая стратегия носит консультативный характер и применяется к стейкхолдерам с высоким уровнем власти, но низким уровнем интереса (группа «С»). Их рекомендуется привлекать в качестве консультантов и согласовывать с ними только важные стратегические решения по фандрайзинговой деятельности. Это наиболее сложная группа. Заинтересованные стороны из этой группы могут быть достаточно пассивны по отношению к фандрайзинговой деятельности фонда, но в отдельных случаях могут возникнуть ситуации, когда их интерес резко вырастет и они могут перейти в группу «D», помешав или поспособствовать принятию стратегических решений благотворительной организации.

Третья стратегия заключается в получении поддержки фандрайзинговой деятельности организации и применяется к стейкхолдерам с низким уровнем власти, но высоким уровнем интересов, второстепенным стейкхолдерам (Группа «В»). Данная группа стейкхолдеров должна быть ознакомлена со всеми ключевыми решениями по фандрайзинговой деятельности, не смотря на то, что она не принимает прямого участия в этих решениях. При этом рекоменду- ется данную группу привлекать к обсуждению возможных проблем и заручаться у нее дополнительной поддержкой по важным решениям. Эти стейкхолдеры могут стать очень важными союзниками в оказании влияния на более могущественных стейкхолдеров (группа «D»).

Четвертая стратегия заключается только в удовлетворении потребностей и используется для стейкхолдеров с низким уровнем власти и низким уровнем интересов, второстепенных стейкхолдеров (Группа «А»). Рекомендуется исключительно учитывать интересы данной группы, не погружая ее в детали фандрайзинговой деятельности и использовать самый низкий уровень информирования.

Стоит отметить, что стратегии управления стейкхолдерами участников фандрайзинговой деятельности следует рассматривать в рамках того или иного проекта (программы) благотворительного фонда. В качестве примера в таблице 1 приведена матрица А. Менделоу «Влияниезначимость» заинтересованных сторон в фандрайзинговой деятельности БФ «Дети наши» в рамках проекта «Не разлей вода - Смоленская область».

Рассмотрим основные аспекты стратегии фандрайзинговой деятельности благотворительного фонда «Дети наши».

Ключевые игроки (группа) D наиболее важны в осуществлении фандрайзинговой деятельности БФ. Ими являются ключевые доноры (коммерческие структуры, грантодатели и частные лица), сотрудники Фонда и фандрайзеры организации, контролирующие органы (Министерство юстиции).

В фандрайзинговой деятельности БФ «Дети наши» в сегменте «С» можно выделить следующие группы стейкхолдеров: государственные партнеры (местные органы опеки и попечительства), Министерство социальной политики Смоленской области, Управление социальной защиты населения Смоленской области, социальные сети, банковские структуры и мобильные телеоператоры.

Очень важно учитывать ожидания стейкхолдеров группы «В», таких как благополучатели и волонтеры, путем предоставление им необходимой информации о предполагаемой фандрайзинговой деятельности благотворительной организации.

При разработке фандрайзинговой деятельности БФ «Дети наши» нельзя забывать и об 
Таблица 1. Матрица А. Менделоу «Влияние-значимость» заинтересованных сторон в фандрайзинговой деятельности БФ в рамках проекта «Не разлей вода - Смоленская область»

\begin{tabular}{|c|c|c|}
\hline $\begin{array}{c}\text { Уровень власти/ } \\
\text { уровень интересов }\end{array}$ & Низкий & Высокий \\
\hline Высокий & $\begin{array}{l}\text { Группа «С» } \\
\text { Государственные партнеры (Местные органы опеки } \\
\text { и попечительства) } \\
\text { Министерство социальной политики Смоленской } \\
\text { области } \\
\text { Управление социальной защиты населения Смо- } \\
\text { ленской области } \\
\text { Социальные сети. } \\
\text { Банковские структуры (с точки зрения оказания } \\
\text { услуг по электронному переводу средств). } \\
\text { Мобильные телеоператоры (с точки зрения оказа- } \\
\text { ния услуг по электронному переводу средств). } \\
\text { СМИ. }\end{array}$ & $\begin{array}{l}\text { Группа «D» } \\
\text { 1. Ключевые доноры: } \\
\text { 1.1 Юридические лица (Коммер- } \\
\text { ческие структуры) } \\
\text { 1.2 Физические лица (Частные } \\
\text { лица) } \\
\text { 1.3. Органы государственной } \\
\text { власти (Грантодатели). } \\
\text { 2. Сотрудники Фонда (фандрай- } \\
\text { зеры) } \\
\text { 3. Контролирующие органы: } \\
\text { Министерство юстиции }\end{array}$ \\
\hline Низкий & $\begin{array}{l}\text { Группа «А» } \\
\text { Близкие родственники, окружение кровной семьи }\end{array}$ & $\begin{array}{l}\text { Группа «В» } \\
\text { Воспитанники и выпускники дет- } \\
\text { ских домов. Принимающие семьи } \\
\text { (включая кровные). Волонтеры. }\end{array}$ \\
\hline
\end{tabular}

удовлетворении потребностей стейкхолдеров и группы «А», в нашем случае это - близкие родственники и окружение кровной семьи детей.

Анализ стратегии взаимодействия БФ «Дети наши» с основными группами заинтересованных сторон на основе анализа матрицы А. Менделоу в рамках проекта «Не разлей вода - Смоленская область», представлен в таблице 2 .

Идея матрицы А. Менделоу в целях упрощения и систематизации стейкхолдеров получила своё развитие в модели Митчелла-Агле-Вуда (рисунок 2), которая была разработана в Высшей школе бизнеса имени Каца, Питтсбургского университета. В модели отражается классификация и представлены основные направления оценки заинтересованных сторон (стейкхолдеров).

Согласно модели, стейкхолдеры могут в разной степени владеть тремя атрибутами среди которых власть, законность (легитимность) и срочность (актуальность) [4]. Она позволяет классифицировать стейкхолдеров после определения наличия тех или иных атрибутов, т.е. позволяет фандрайзеру принимать необходимые управленческие решения по обеспечению сбалансированности участников фандрайзинговой деятельности благотворительной организации.

Для усиления анализа значимости стейкхолдеров фандрайзинговой деятельности благотворительного фонда «Дети наши» применим модель Митчелла. Модель Митчелла идентифицирует значимость заинтересованных сторон. «Для этого выбираются релевантные атрибуты или свойства, которыми они могут обладать и от которых зависит их значимость. Каждая группа или индивид оцениваются на предмет обладания этими атрибутами, в результате чего становится возможным отнести их к тому или иному классу значимости, элементы которого обладают (и не обладают) одинаковым набором атрибутов. Эти классы можно упорядочить в зависимости от важности соответствующего им набора атрибутов. Тогда значимость каждой заинтересованной стороны оценивается как значимость класса, в который она входит» (таблица 3).

Таким образом, по увеличению значимости стейкхолдеров фандрайзинговой деятельности благотворительного фонда «Дети наши» можно распределить в следующем порядке:

Латентная группа (1 атрибут):

- Требующая группа - Близкие родственники, окружение кровной семьи.

Ожидающая группа (2 атрибута):

- Доминирующая группа (власть, законность) - Государственные органы (с точки зрения влияния со стороны законов), Государственные партнеры (Местные органы опеки и попечительства), Министерство социальной политики Смоленской области, Управление социальной защиты населения Смоленской области,

- Зависимая группа (законность, срочность) - благополучатели; Банковские структуры (с точки зрения оказания услуг по электронному переводу средств), Мобильные телеоператоры (с точки зрения оказания услуг 
Таблица 2. Анализ стратегии взаимодействия БФ «Дети наши» с основными группами заинтересованных сторон в рамках проекта «Не разлей вода - Смоленская область»

\begin{tabular}{|c|c|c|c|c|c|}
\hline $\begin{array}{c}\text { Стейк- } \\
\text { холдеры }\end{array}$ & $\begin{array}{c}\text { Интерес к фан- } \\
\text { драйзинговой } \\
\text { деятельности }\end{array}$ & $\begin{array}{c}\text { Влияние на фан- } \\
\text { драйзинговую } \\
\text { деятельность }\end{array}$ & $\begin{array}{c}\text { Относительная } \\
\text { значимость для } \\
\text { фандрайзинговой } \\
\text { деятельности }\end{array}$ & $\begin{array}{c}\text { Какое действие } \\
\text { необходимо для } \\
\text { стейкхолдера }\end{array}$ & $\begin{array}{c}\text { Какие действия } \\
\text { должен предпри- } \\
\text { нимать БФ }\end{array}$ \\
\hline $\begin{array}{c}\text { Группа } \\
\text { «в» }\end{array}$ & высокий & низкое & высокая & $\begin{array}{l}\text { Получение } \\
\text { финансовых и } \\
\text { нефинансовых } \\
\text { ресурсов }\end{array}$ & $\begin{array}{l}\text { Информировать о } \\
\text { выделяемым им } \\
\text { ресурсам }\end{array}$ \\
\hline $\begin{array}{c}\text { Группа } \\
\text { «D» }\end{array}$ & высокий & высокое & высокая & $\begin{array}{l}\text { Поддержка фан- } \\
\text { драйзинговой } \\
\text { деятельности } \\
\text { по, выделению } \\
\text { ресурсов }\end{array}$ & $\begin{array}{l}\text { Информировать } \\
\text { о направлениях } \\
\text { расходования } \\
\text { выделяемыми } \\
\text { ими ресурсами и } \\
\text { искать поддержки }\end{array}$ \\
\hline $\begin{array}{c}\text { Группа } \\
\text { «C» }\end{array}$ & низкий & высокое & высокая & $\begin{array}{l}\text { Рост спектра ус- } \\
\text { луг, оказываемых } \\
\text { воспитанникам } \\
\text { и выпускникам } \\
\text { детских домов. }\end{array}$ & $\begin{array}{l}\text { Своевременная, } \\
\text { полная, прозрач- } \\
\text { ная отчетность о } \\
\text { реальных резуль- } \\
\text { татах }\end{array}$ \\
\hline $\begin{array}{c}\text { Группа } \\
\text { «A» }\end{array}$ & низкий & низкое & низкая & $\begin{array}{l}\text { Рост количества } \\
\text { детей передава- } \\
\text { емых на воспи- } \\
\text { тание в кровные } \\
\text { семьи }\end{array}$ & $\begin{array}{l}\text { Развернутая ин- } \\
\text { формация о вы-- } \\
\text { сокой значимости } \\
\text { кровных семей в } \\
\text { воспитании детей } \\
\text { и о возможностях } \\
\text { фонда по оказа-- } \\
\text { нию помощи. }\end{array}$ \\
\hline
\end{tabular}

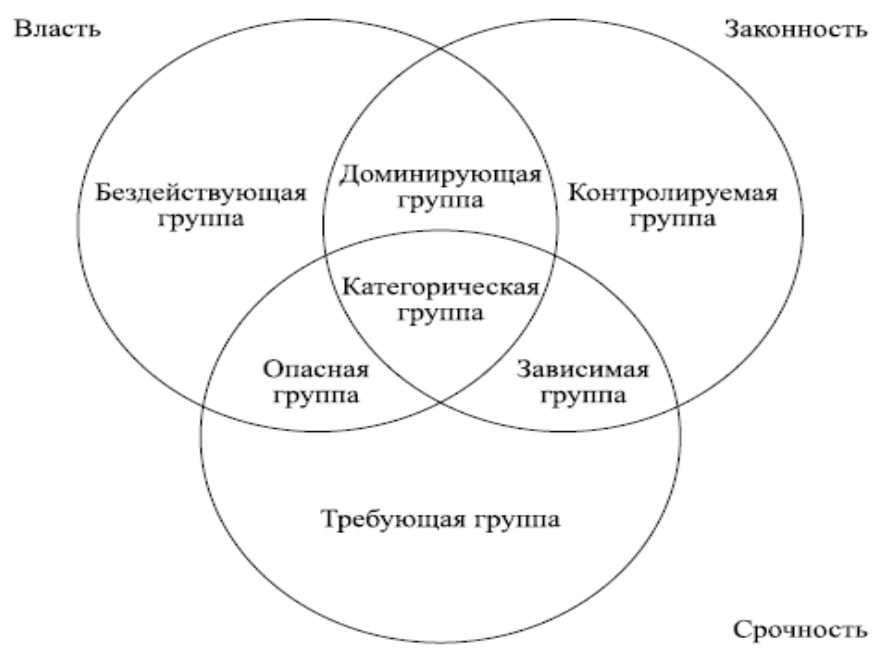

Puc. 2. Модель идентификации значимости заинтересованных сторон (Митчелла-Агле-Вуда) 
Таблица 3. Атрибуты стейкхолдеров благотворительного фонда «Дети наши» в рамках проекта «Не разлей вода - Смоленская область»

\begin{tabular}{|c|c|c|c|}
\hline Стейкхолдер/наличие атрибута & Власть & Законность & Срочность \\
\hline $\begin{array}{l}\text { Благотворители: Органы государственной власти (Грантодатели). } \\
\text { Коммерческие структуры. Частные лица }\end{array}$ & + & & + \\
\hline Контролирующие органы (Министерство юстиции) & + & + & + \\
\hline $\begin{array}{l}\text { Государственные органы (с точки зрения влияния со стороны зако- } \\
\text { нов): } \\
\text { Государственные партнеры (Местные органы опеки и попечитель- } \\
\text { ства) } \\
\text { Министерство социальной политики Смоленской области } \\
\text { Управление социальной защиты населения Смоленской области }\end{array}$ & + & + & \\
\hline $\begin{array}{l}\text { Благополучатели: Воспитанники и выпускники детских домов. } \\
\text { Принимающие семьи (включая кровные). }\end{array}$ & & + & + \\
\hline Волонтеры & + & & + \\
\hline Близкие родственники, окружение кровной семьи & & & + \\
\hline $\begin{array}{l}\text { Банковские структуры (с точки зрения оказания услуг по электрон- } \\
\text { ному переводу средств). }\end{array}$ & & + & + \\
\hline СМИ & + & & + \\
\hline Социальные сети & + & & + \\
\hline $\begin{array}{l}\text { Мобильные телеоператоры (с точки зрения оказания услуг по элек- } \\
\text { тронному переводу средств). }\end{array}$ & & + & + \\
\hline
\end{tabular}

по электронному переводу средств).

- Опасная группа (власть, срочность) - Благотворители, СМИ, социальные сети, волонтеры.

- Категорическая группа (3 атрибута) - Контролирующие органы (Министерство юстиции).

На основе проведенного анализа можно выделить следующие стратегии управления стейкхолдерами участников фандрайзинговой деятельности БФ «Дети наши»:

1. Благотворительному фонду «Дети наши» следует заручиться поддержкой и связями в контролирующих органах (категорическая группа), поскольку они оказывают наибольшее влияние на фандрайзинговую деятельность благотворительной организации, от них зависит не просто финансирование программ БФ, но и его существование вообще. Кроме того, наличие связей в доминирующей группе (государственные органы и партнеры) также будет залогом успешной реализации фандрайзинговой стратегии.

2. БФ «Дети наши» при разработке фандрайзинговой стратегии и последующей ее реализации для отношений с опасной группой благотворителями, СМИ, социальными сетями, волонтерами - следует принимать во внимание главные их интересы, Так, например, если коммерческим организациям, как донорам, важен пиар их деятельности, то следует это принять во внимание, поскольку они являются основополагающим источником финансирования анали- зируемого фонда. Аналогичная схема действий должна быть и с другими заинтересованными сторонами этой группы.

3. Так как стейкхолдеры из зависимой группы - это лица, на которые фонд направляет свою непосредственную фандрайзинговую деятельность, то оценка их интересов находится в прямой обязанности фонда.

При разработке стратегии управления стейкхолдерами участниками фандрайзинговой деятельности БФ следует смоделировать взаимоотношения со стейкхолдерами. На этом этапе происходит выстраивание отношений со стейкхолдерами на основе выбора оптимальной модели их взаимодействия: манипулятивной, информирования, взаимопонимания и социального партнерства. Анализ стратегии взаимодействия БФ «Дети наши» с основными группами заинтересованных сторон в рамках проекта «Не разлей вода - Смоленская область» на основе анализа матрицы А. Менделоу представлен в таблице 4.

Таким образом, стратегии взаимодействия БФ «Дети наши» с основными группами заинтересованных сторон построены на четырех группах моделей: манипулятивной, информирования, взаимопонимания и социального партнерства.

Во взаимоотношениях БФ «Дети наши» и благотворителей (Группа «D») присутствуют 
Таблица 4. Анализ стратегии взаимодействия БФ «Дети наши» с основными группами заинтересованных сторон в рамках проекта «Не разлей вода - Смоленская область» на основе анализа матрицы А.Менделоу

\begin{tabular}{|c|c|c|c|c|}
\hline $\begin{array}{c}\text { Стекхолдеры / моде- } \\
\text { ли взаимодействия } \\
\text { с БФ }\end{array}$ & Манипулятивная & Информирования & Взаимопонимания & $\begin{array}{l}\text { Социального } \\
\text { партнерства }\end{array}$ \\
\hline $\begin{array}{l}\text { Группа «В» } \\
\text { Воспитанники и } \\
\text { выпускники детских } \\
\text { домов. Принимаю- } \\
\text { щие семьи (включая } \\
\text { кровные). Волон- } \\
\text { теры. }\end{array}$ & & \begin{tabular}{|l} 
Информировать о \\
выделяемым им \\
ресурсам \\
специфики про- \\
блемного поля вы- \\
пускников и объема \\
оказываемой им \\
помощи
\end{tabular} & $\begin{array}{l}\text { Диалог; } \\
\text { Обратная связь }\end{array}$ & $\begin{array}{l}\text { Систематическая } \\
\text { работа со стейк- } \\
\text { холдером; клиент } \\
\text { становится соавто- } \\
\text { ром продукта, а не } \\
\text { просто потребите- } \\
\text { лем }\end{array}$ \\
\hline $\begin{array}{l}\text { Группа «D» } \\
\text { 1. Ключевые доно- } \\
\text { ры: } \\
\text { 2. Сотрудники Фон- } \\
\text { да (фандрайзеры) } \\
\text { 3. Контролирующие } \\
\text { органы: Министер- } \\
\text { ство юстиции }\end{array}$ & $\begin{array}{l}\text { Разработка фан- } \\
\text { драйзинговой про- } \\
\text { граммы для получе- } \\
\text { ния поддержки. } \\
\text { Благодарственные } \\
\text { письма. } \\
\text { Рассылки. } \\
\text { Создание писем. }\end{array}$ & $\begin{array}{l}\text { Финансовые ежеме- } \\
\text { сячные отчеты о со- } \\
\text { бранных средствах } \\
\text { в ходе проведенных } \\
\text { мероприятий } \\
\text { Информировать } \\
\text { о направлени- } \\
\text { ях расходования } \\
\text { выделяемыми ими } \\
\text { ресурсами } \\
\text { Информирован- } \\
\text { ность о работе } \\
\text { фонда и проводи- } \\
\text { мых им акциях по } \\
\text { всем возможным } \\
\text { каналам. }\end{array}$ & $\begin{array}{l}\text { Диалог; } \\
\text { Обратная связь }\end{array}$ & $\begin{array}{l}\text { Систематическая } \\
\text { работа со стейк- } \\
\text { холдером; клиент } \\
\text { становится соавто- } \\
\text { ром продукта, а не } \\
\text { просто потребите- } \\
\text { лем }\end{array}$ \\
\hline \begin{tabular}{|l} 
Группа «С» \\
Государственные \\
партнеры \\
Социальные сети. \\
Банковские структу- \\
ры Мобильные теле- \\
операторы СМИ..
\end{tabular} & $\begin{array}{l}\text { Разработка фан- } \\
\text { драйзинговой про- } \\
\text { граммы для получе- } \\
\text { ния поддержки. }\end{array}$ & $\begin{array}{l}\text { Своевременная, } \\
\text { полная, прозрачная } \\
\text { отчетность о реаль- } \\
\text { ных результатах по } \\
\text { всем возможным } \\
\text { каналам. } \\
\text { Анализ данных о } \\
\text { числе детей, воспи- } \\
\text { тываемых в семьях. }\end{array}$ & $\begin{array}{l}\text { Равноправные } \\
\text { взаимоотношения } \\
\text { как с партнерами. } \\
\text { Помощь в развитии } \\
\text { БФ Государство } \\
\text { игнорирует подоб- } \\
\text { ные организации, } \\
\text { относится к ним } \\
\text { равнодушно. Госу- } \\
\text { дарство пытается } \\
\text { установить полный } \\
\text { контроль над дея- } \\
\text { тельностью БО. } \\
\text { Государство пыта- } \\
\text { ется искоренить и } \\
\text { уничтожить БО. }\end{array}$ & $\begin{array}{l}\text { Систематическая } \\
\text { работа со стейк- } \\
\text { холдером; клиент } \\
\text { становится соавто- } \\
\text { ром продукта, а не } \\
\text { просто потребите- } \\
\text { лем }\end{array}$ \\
\hline \begin{tabular}{|l} 
Группа «А» \\
Близкие родствен- \\
ники, окружение \\
кровной семьи
\end{tabular} & & $\begin{array}{l}\text { Развернутая инфор- } \\
\text { мация о высокой } \\
\text { значимости кров- } \\
\text { ных семей в воспи- } \\
\text { тании детей и о воз- } \\
\text { можностях фонда по } \\
\text { оказанию помощи. } \\
\text { Анализ данных о } \\
\text { социальной адапта- } \\
\text { ции выпускников } \\
\text { Анализ данных о } \\
\text { числе детей, воспи- } \\
\text { тываемых в семьях. }\end{array}$ & $\begin{array}{l}\text { Диалог; } \\
\text { Обратная связь } \\
\text { Беседы }\end{array}$ & \\
\hline
\end{tabular}


4 типа моделей. Наибольшую часть финансовых средств БФ «Дети наши» получает от юридических лиц, это довольно актуально, так как в последнее время появляется социальноответственный бизнес, который создает себе имидж посредством включения в благотворительную деятельность. Однако здесь у БФ «Дети наши» существуют проблемы взаимодействия: многие предприниматели считают, что благотворительная деятельность не нужна, или что они не обязаны этим заниматься. Здесь встает вопрос мотивов. Как и у других спонсоров, они могут быть двузначными: либо корыстными, либо бескорыстными; это зависит от предпринимателя и его возможностей заниматься благотворительной деятельностью.

Взаимоотношения властных структур и БФ «Дети наши» (Группа «С») также присутствуют 4 типа моделей. Наибольший интерес представляет модель - информирования, т.е. отношения являются «прозрачными», носящие открытый характер, при том, что сейчас существенная часть населения нашей страны относится к деятельности подобных организаций довольно скептически. Если же информированность о деятельности БФ «Дети наши» повысится, повысится и его престижность и государство станет очевидным союзником для других благотворительных фондов, для которых оно подчас бывает «тотальным диктатором» и контроллером. Однако из-за отсутствия законодательной базы в данном вопросе благотворительный фонд имеет небольшую степень влияния на государственные учреждения (детские дома) и детей, которые там находятся. Поэтому сложно говорить о том, какой модели взаимодействия они придерживаются, но то, что они положительно влияют друг на друга не вызывает сомнений. Как и государство в целом, детские дома также нуждаются в помощи со стороны БФ, поэтому всячески содействуют его развитию и предоставляют возможность организовывать различные мероприятия для их детей.

Отношения БФ «Дети наши» со средствами массовой информации (Группа «С») можно охарактеризовать как «просящие» отношения.
Сложно сказать, существует ли определенная модель взаимодействия у СМИ и благотворительных организаций, однако то, что они взаимозависимы, не подлежит сомнению. В зависимости от того, какие цели преследуют оба субъекта, будет складываться тот или иной тип взаимоотношений. Модели взаимодействия средств массовой информации, как заинтересованного субъекта фандрайзинговой деятельности, и благотворительных организаций предполагают «рекламирование» деятельности последних в СМИ. Так, примерами таких взаимодействий могут быть сайты, реклама в других фондах, информациях в организациях-спонсорах, рекламные ролики, стенды, плакаты (баннеры), а также акции и мероприятия, которые освещаются в СМИ. Целью такого взаимодействия в конкретном случае является привлечение внимания общественности к БФ «Дети наши», к его деятельности и к тем социальным проблемам, которые он призван решать.

По результатам анализа можно сделать вывод, что при реализации стратегии управления стейкхолдерами в фандрайзинговой деятельности БФ «Дети наши» в рамках проекта «Не разлей вода - Смоленская область» наладил четкие, обоюдно выгодные отношения со всеми стейкхолдерами, поскольку они имеют колоссальное влияние на деятельность фонда. Благодаря хорошим партнерским отношениям с главными стейкхолдерами и слаженной работе коллектива БФ «Дети наши» его фандрайзинговая деятельность отвечает современным требованиям.

Таким образом, определение механизмов вовлечения каждого стейкхолдера в фандрайзинговую деятельность благотворительной организации и использование эффективных стратегий управления их действиями, могут в конечном итоге привести к повышению социальной значимости всей деятельности некоммерческой организации и усилению ее фандрайзингового направления, призванного привлекать благотворительные средства (гранты, субсидии, пожертвования, имущество и пр.) от государства, бизнес-компаний и населения для оказания адресной помощи проектов.

\section{Библиографический список}

1. Басова М. М. Основные критерии эффективности фандрайзинга в российских НКО // Экономические науки. 2019. № 175. C. $154-162$.

2. Басова М. М. Основные подходы к обеспечению сбалансированности интересов участников фандрайзинговой деятельности НКО // Экономические науки. 2019. № 176. С. 127-134. 
3. Басова М.М. Особенности составления нефинансовой отчетности в социально ориентированных некоммерческих организациях // Вестник Московского университета им. С.Ю.Витте. Серия 1: Экономика и управление. 2017. № 3 (22). С. 50-53.

4. Басова М. М. Основные проблемы корпоративной социальной ответственности бизнеса и пути их решения // Стратегии бизнеса. 2017. № 2 (34). С. 16-20.

5. Возмилкина Е.Н. Фандрайзинг в социальной сфере // Научно-методический электронный журнал «Концепт». - 2016. - Т. 11.- С. 4066-4070. [Электронный ресурс] - URL: http://e-koncept.ru/2016/86852.htm.

6. Галимзянов, М.Д. Методики анализа стейкхолдеров проекта / М. Д. Галимзянов.-Текст: непосредственный // Молодой ученый. - 2019. - № 35 (273). - C. 35-37. - URL: https://moluch.ru/archive/273/62188/ (дата обращения: 10.08.2020).

7. Корнеева И.Е. Фандрайзинг в российских некоммерческих организациях: результаты эмпирического исследования // Мониторинг общественного мнения: Экономические и социальные перемены. 2016 № 4 С. 48-66.

8. Общественное объединение и некоммерческие организации: деятельность и поддержка: монография / под ред. Т.Э. Петровой.-М.: ИНФРА-М, 2018.-118 с

9. Официальный сайт Благотворительного Фонда «Дети наши», [Электронный ресурс] - URL: https://detinashi. $\mathrm{ru}$ (Дата обращения 28.05.2020).

10. Что такое DRM и как она поможет благотворительным организациям наладить работу? [Электронный реcypc] - URL: https://takiedela.ru/news/2018/03/14/drm// (Дата обращения 11.06.2020) 